\title{
Comparison of National Growth Standards for Turkish Infants and Children with World Health Organization Growth Standards
}

\author{
(D) Rüveyde Bundak¹, (D) Zehra Yavaş Abalı2, (D) Andrzej Furman³, (D) Feyza Darendeliler2, (D) Gülbin Gökçay4 , (D Firdevs Baş², \\ (D) Hülya Günöz², (D) Olcay Neyzi² \\ 1 University of Kyrenia, Faculty of Medicine, Department of Pediatric Endocrinology, Kyrenia, North Cyprus \\ 2istanbul University, istanbul Faculty of Medicine, Department of Pediatric Endocrinology, Istanbul, Turkey \\ ${ }^{3}$ Boğaziçi University, Institute of Environmental Sciences, Istanbul, Turkey \\ 4 istanbul University, Institute of Child Health, Department of Social Pediatrics, Istanbul, Turkey
}

\begin{abstract}
What is already known on this topic?
Incorporation of World Health Organization (WHO) standards into pediatric practice has been the subject of debate in many countries, particularly those using national reference data for child growth assessment.
\end{abstract}

\section{What this study adds?}

WHO growth standards do not reflect the growth of Turkish children and may substantially alter the prevalence of short stature and underweight in the $0-5$ years age group.

\section{Abstract}

Objective: Using World Health Organization (WHO) standards in pediatric practice is still controversial in many countries. It is suggested that national growth charts best reflect the genetic and ethnic characteristics of a population. The aim of this study was to compare length/height, body weight, and body mass index (BMI) in healthy Turkish children of ages 0 to 18 with those proposed by WHO as the international growth standards.

Methods: The data of Turkish children were collected from infant/child population aged 0-5 years (2391 boys, 2102 girls) and children of ages between 6-18 years (1100 boys, 1020 girls). For comparison, the $50^{\text {th }}, 3^{\text {rd }}$, and $97^{\text {th }}$ percentile curves for length/height, weight, and BMI in Turkish children were plotted together with respective WHO data.

Results: Heights were essentially similar in the Turkish and WHO data at ages between 3-10 years. Turkish children were markedly taller compared to the WHO standards after the age of 10 years. Evaluation of the $3^{\text {rd }}$ percentile data revealed that Turkish boys were shorter than the WHO subjects in the first 2 years of life. From 6 months of age, Turkish children showed higher weight for age values in the $3^{\text {rd }}$, $50^{\text {th }}$, and $97^{\text {th }}$ percentiles. In all age groups between 6 months and 3 years, and in between 6-18 years of age, Z-score values, as well as the $50^{\text {th }}, 15^{\text {th }}, 85^{\text {th }}$, and $95^{\text {th }}$ percentile values were higher in Turkish children. The differences were particularly noteworthy at ages $1-2$ years and in the pubertal years.

Conclusion: WHO growth standards do not reflect the growth of Turkish children and may substantially alter the prevalence of short stature and underweight in Turkish children in the 0-5 years age group. When assessing the nutritional and growth status of children, national growth standards may be more appropriate.

Keywords: Growth charts, Turkish children, WHO standards 


\section{Introduction}

Monitoring the growth and development of each individual child from birth onwards is an essential part of pediatric care. The monitoring of growth enables the physician to diagnose aberrations in physical growth at an early stage and to initiate treatment when indicated. Anthropometry is not only an important diagnostic method in the evaluation of the growth of individual children, but is also a reliable indicator of the nutritional state of a community. Growth charts are important tools in the assessment of children's development. Local growth charts, if prepared in accordance with standard methodology, best reflect the genetic and ethnic characteristics of a population. Thus, in almost all developed countries, national or local growth charts, based on measurements of healthy infants/children living in those communities, are used in the assessment of the growth of infants and children. The World Health Organization (WHO) standards have been in use, mainly in countries that have not yet developed their national growth charts $(1,2)$.

In an effort to document the hypothesis that provision of optimal nutrition and environmental conditions can eliminate the differences in growth resulting from ethnic, nutritional, socioeconomic, and climatic factors and to advocate that the same growth charts can be used in all countries, WHO has created international standard growth charts for infants and children of ages 0 to 5, based on data obtained from six different countries (1). In contrast, the "international growth standards" proposed by WHO for children aged 5-18 years are based on the 1977 growth data of children from the United States of America (USA) (2).

Despite the statement that these international standards are valid for all countries, there are a great number of publications from European and Asian countries stating that their findings do not conform to the WHO charts $(3,4,5,6,7,8,9)$. On the other hand, WHO charts are recommended for use in the United Kingdom, the USA, and France. Prevention of obesity constitutes the main reasoning lying behind this recommendation $(10,11,12,13)$.

This study was designed to compare body weight, length/ height, and body mass index (BMI) values in healthy Turkish children of ages 0 to 18 with those proposed by WHO as international growth standards.

\section{Methods}

The data on Turkish children presented in this paper are based on previously reported studies. One of these studies was conducted on an infant/child population aged 0-5 years attending the Well Child Clinic of a University Hospital between the years 1992 and 2006 (14). Preterm infants born before 37 completed gestational weeks were not included in this study. Families attending the Well Child Clinic are relatively homogeneous in socio-economic and cultural levels. The parents of all subjects in this study were literate and the majority of the mothers had at least 5 years of schooling. The majority of the fathers were high school graduates. The routine follow-up schedule of the Clinic for the first year of life started at age 2 weeks and included visits at $1^{\text {st }}, 2^{\text {nd }}, 3^{\text {td }}, 4^{\text {th }}, 5^{\text {th }}, 6^{\text {th }}, 9^{\text {th }}, 12^{\text {th }}, 15^{\text {th }}$, and $18^{\text {th }}$ months and every 6 months thereafter until 5 years of age. A complete physical examination including anthropometric measurements was performed at each visit. Pediatric residents and nurses provided breastfeeding counseling. All data on the infants/children attending the Clinic were recorded by computer. Length/height, weight, and head circumference measurements were performed by two trained nurses. The naked weights were obtained on an electronic digital scale (Seca, 727; Kimeks Chemical Materials and Anitary Appliances Trade. Inc. Norm İş Merkezi, Şişli-İstanbul; e-mail: eticaret@kimeks.com), accurate to $5 \mathrm{~g}$. A locally manufactured standard measuring board, with increments in millimeters, was used to measure supine length. After the age of 3 years, standing height was measured using a Leicester Height Measure (Child Growth Foundation, manufactured by Invicta Plastics Ltd, Roadby, Leicester, UK). The study sample consisted of 2391 boys and 2102 girls between 15 days and 60 months of age. The data set included a total of 19523 boys' and 16807 girls' measurements for length/height, as well as 19714 boys' and 17035 girls' measurements for weight. BMI values were calculated from weight and height measurements of 19433 boys and 16740 girls. The mean number of measurements per child was $8.2 \pm 3.6$.

The data on children of ages 6 to 18 years are also based on previous studies $(15,16,17)$. The study sample consisted of 1100 boys and 1020 girls attending primary and secondary schools located in six different districts of Istanbul city. All six schools were located in relatively well-off districts. The data were collected between the years 1989 and 2002 by biannual visits to the schools by a team consisting of one pediatrician, two trained technicians, and two physicians training in pediatrics. Using the school files, all children in one class at a time, whose birthdays were \pm 3 months from the prospective date of examination, were selected as subjects to be measured at the next visit. Information on the study and on the importance of height and weight measurements was given to children in groups. Written parental consent was obtained with the help of the school administration. Children who refused to cooperate were excluded. Younger children (6-10 years) constituted the 
subjects in the first 3-4 years of the study and over time, measurements were repeated on the same children but other children were also added into the study to provide adequate numbers for the older age groups. Thus, the total sample consists of a mixture of children followed longitudinally over different periods of time. Chronological age was computed from the birth date reported by the child and verified by the school files. If these two sources disagreed, the child was not included in the study. Chronic or debilitating disease, assessed by history and a brief physical examination, was also a reason for exclusion. Heights were measured in a standing position with bare feet, using a portable measuring device (the Leicester height measure, Invicta Plastics Ltd, Roadby, Leicester, UK). A portable scale, sensitive to $0.1 \mathrm{~kg}$, was used for weight measurements, which were conducted with the children in their underclothes. All measurements were performed by the same two trained technicians. Height and head circumference measurements were repeated twice and the mean value was calculated. After all data were collected, the subjects were allocated to socioeconomic classes (SEC), using an arbitrary classification based on the education level of both parents and the occupation of the fathers $(15,18)$. Since no significant differences were noted in height and weight values between SEC classes 1 and 2 , data on children falling into both classes (SEC 1 and 2) were included in this presentation. The dates of birth of the children ranged between 1974 and 1989. The data set for children of ages 6 to 18 included a total of 6007 height measurements for boys and 5657 for girls, 6008 weight measurements for boys, and 5647 for girls. The mean number of measurements per child was $5.5 \pm 3.3$. With the exception of age groups $6,17.5$, and 18 years, each half age group included measurements over 100 subjects.

The study was approved by the Institutional Ethical Review Board of İstanbul University, İstanbul Faculty of Medicine (protocol no: 1272, date: 26.06.2015).

\section{Statistical Analysis}

The final data were obtained by the merging and smooth transition of the anthropometric results of younger children with those of children older than six years (17). The LMS method, developed by Cole, was used as the statistical technique for reference construction in all the above studies $(19,20)$. For comparison, the $50^{\text {th }}, 3^{\text {rd }}$, and $97^{\text {th }}$ percentile curves for length/height, weight, and BMI in Turkish boys and girls were plotted together with the respective WHO data. The horizontal line denoted as " 0 " represents the WHO data.

\section{Results}

Figure 1 depicts Z-score values, as well as the $50^{\text {th }}, 3^{\text {rd }}$, and $97^{\text {th }}$ percentile values, for length/height for age in Turkish girls and boys versus the WHO standards. Values pertaining to children aged 0 to 3 years are shown on the left and those for older children on the right panel of the figure. WHO values are expressed as the "0 lines" in the figures. It should be noted that the Z-score, as well as the 50th percentile values, were comparable to WHO standards in the first 3 months and between 3-10 years of life. Higher values for length/height existed in the age groups between 3 months and 3 years. The differences ranged between 0.1 standard deviation (SD) and $0.5 \mathrm{SD}$ (roughly between $0.3 \mathrm{~cm}$ and $1.2 \mathrm{~cm}$ ). Heights were essentially similar in the Turkish and WHO data at ages between 3 and 10 years. However, Turkish children were notably taller compared to the WHO curves after age 10 years, showing differences as great as $1.7 \mathrm{~cm}$. The $97^{\text {th }}$ percentile values also showed differences similar to those noted in the $50^{\text {th }}$ percentile curves and the Z-score values. On the other hand, an evaluation of the $3^{\text {rd }}$ percentile data revealed that Turkish boys were shorter than the WHO subjects in the first 2 years of life, a difference in the range of $0.5 \mathrm{~cm}$ and $1.4 \mathrm{~cm}$. Third percentile values in Turkish boys were comparable to the WHO standards between ages 2 years and 10 years. As to girls, the $3^{\text {rd }}$ percentile values for length/height were comparable to WHO standards between ages 0 to 10 years. In both sexes, $3^{\text {rd }}$ percentile values for height were greater in Turkish children. Weight for age values in Turkish children as compared with WHO values are shown in Figure 2. It is notable that, starting at age 6 months, Turkish children showed higher weight for age values in the $3^{\text {rd }}, 50^{\text {th }}$, and $97^{\text {th }}$ percentiles as well as in the Z-score charts.

Percentile curves and Z-score curves for BMI in Turkish children as compared to the WHO standards are depicted in Figure 3. In all age groups between 6 months and 3 years, and in age groups between 6 and 18 years, Z-score values, as well as the $50^{\text {th }}, 15^{\text {th }}, 85^{\text {th }}$, and $95^{\text {th }}$ percentile values were greater in Turkish children. The differences were particularly noteworthy (as high as $1.7 \mathrm{~cm}$ ) at ages $1-2$ years and in the pubertal years. BMI values in children aged between 3 to 6 years were comparable to WHO standards.

Prevalence estimates of short stature in the children's sample according to the Turkish and WHO standards and prevalence estimates of obesity in the children's sample according to the Turkish and WHO standards are illustrated in Figure 4 and Figure 5.

In the age groups from 0 to 3 years, absolute differences between Turkish children and WHO standards, which were 

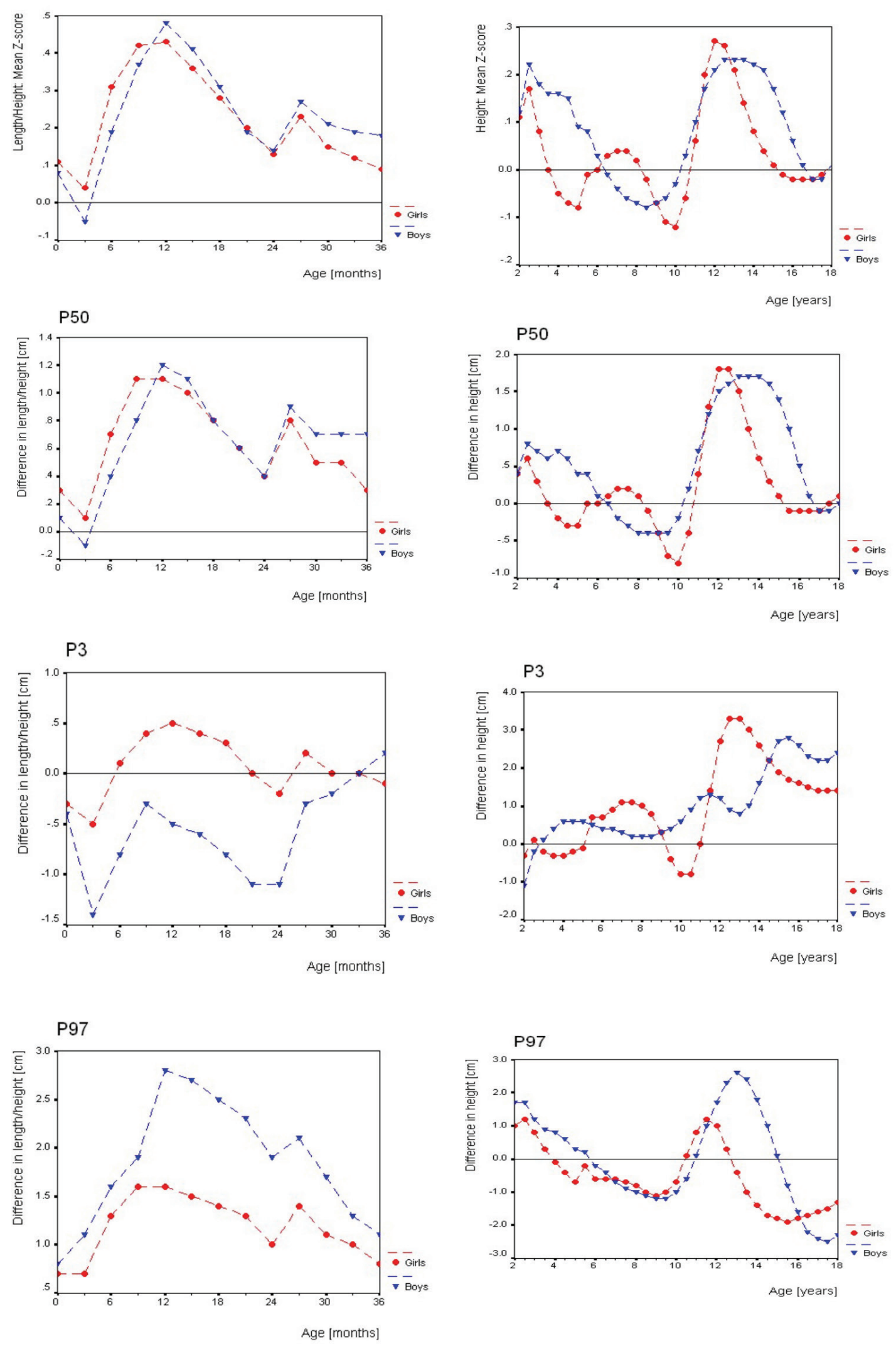

Figure 1. Z-score and percentile values for length/height for age in Turkish children versus the World Health Organization (WHO) standards (values pertaining to children aged 0 to 3 years are shown on the left and those for older children on the right panel of the figure. WHO values are expressed as the "0 line" in the figures) 

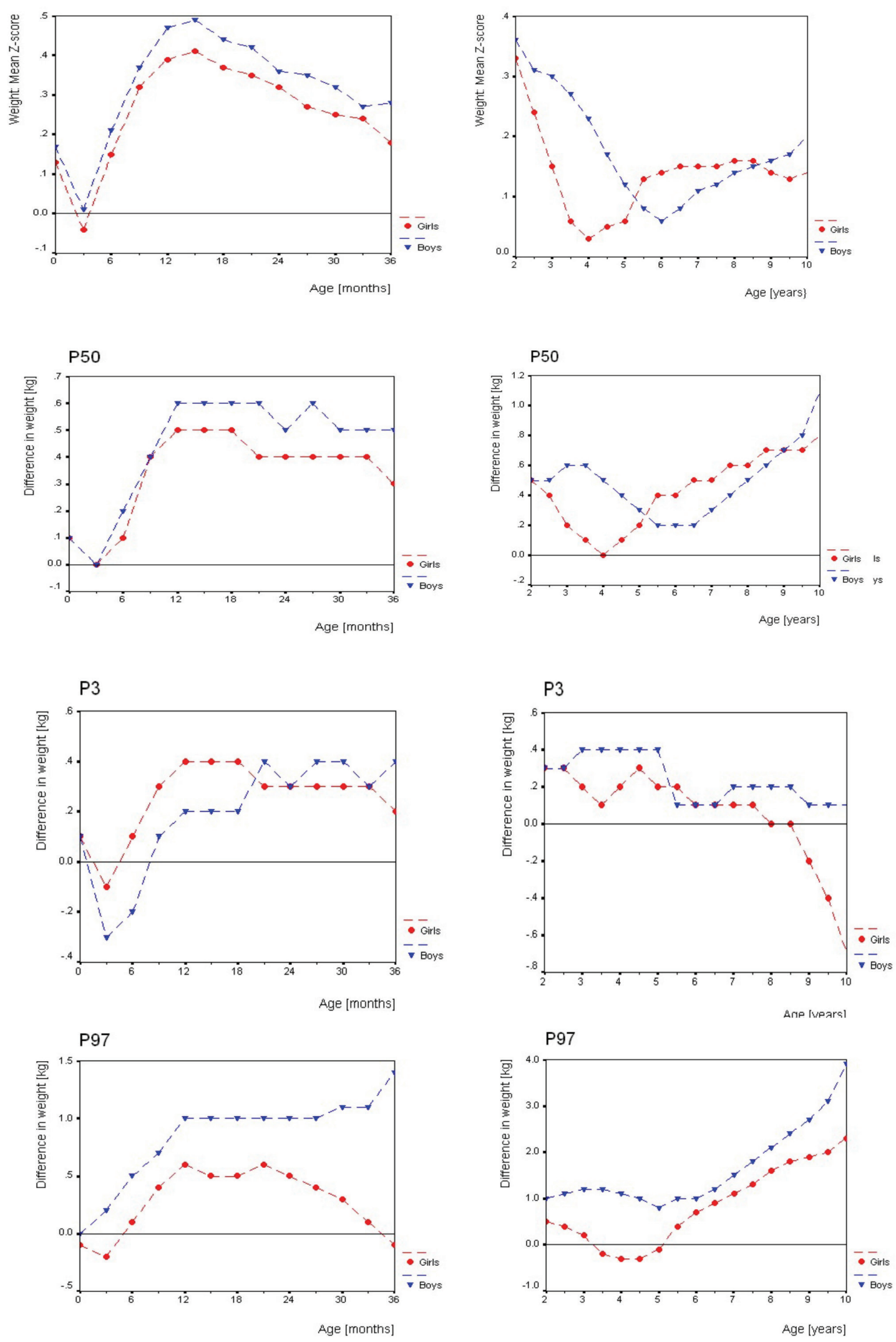

Figure 2. Z-score and percentile values for weight for age in Turkish children versus the World Health Organization (WHO) standards (values pertaining to children aged 0 to 3 years are shown on the left and those for older children on the right panel of the figure. WHO values are expressed as the "0 line" in the figures) 

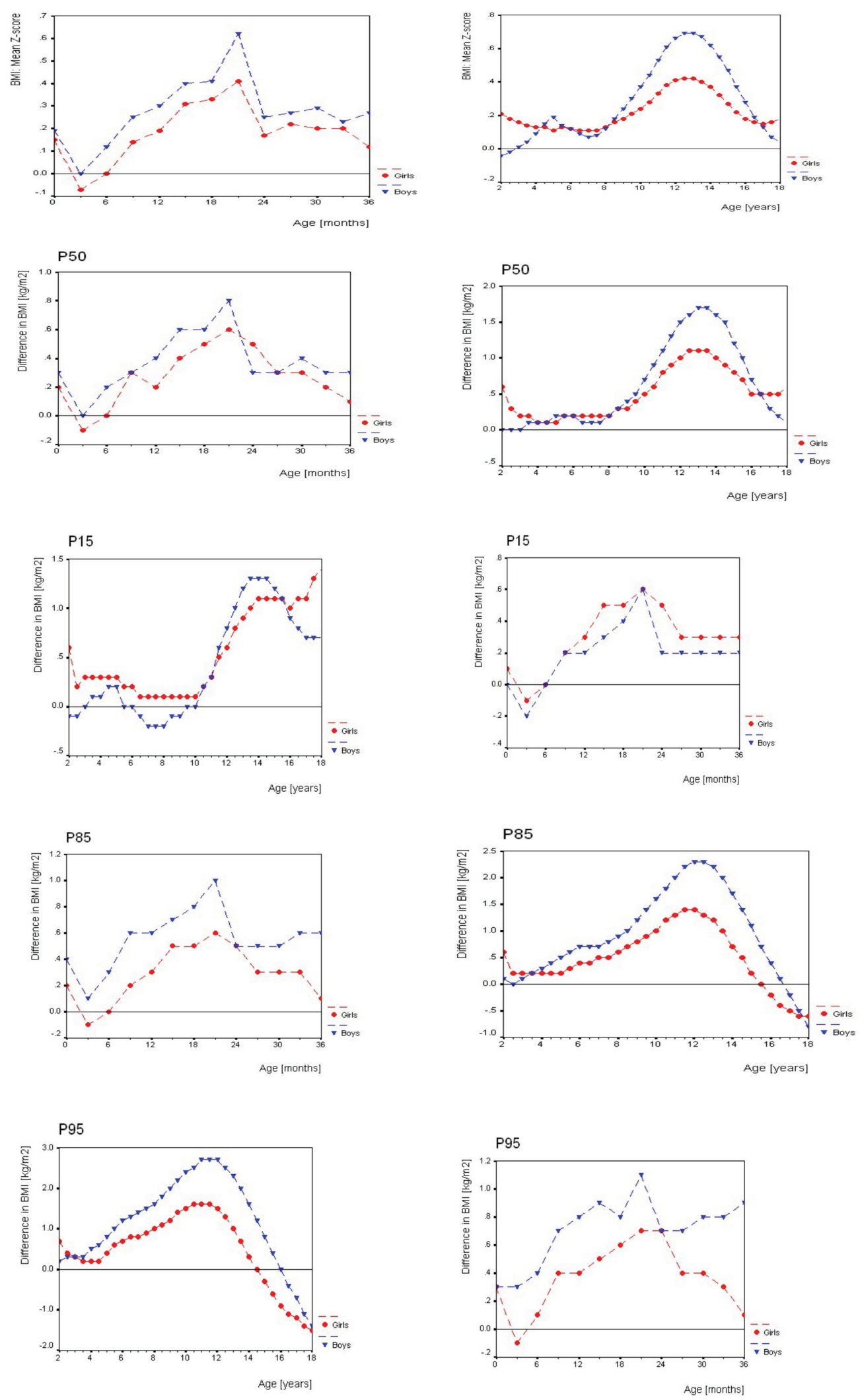

Figure 3. Z-score and percentile values for body mass index for age in Turkish children versus the World Health Organization (WHO) standards (values pertaining to children aged 0 to 3 years are shown on the left and those for older children on the right panel of the figure. WHO values are expressed as the "0 line" in the figures) 


\section{Weight and height less then -2SDS}

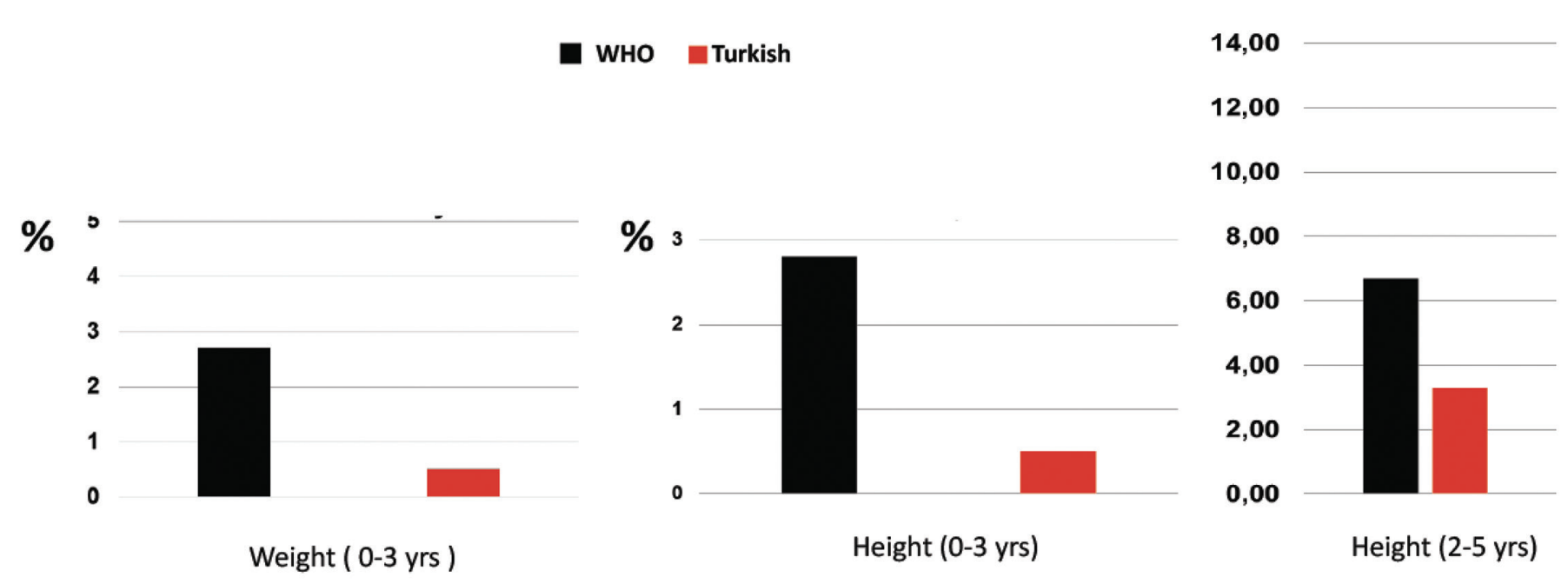

Figure 4. Prevalence estimates of short stature in the children's sample according to the Turkish and World Health Organization standards

SDS: standard deviation score

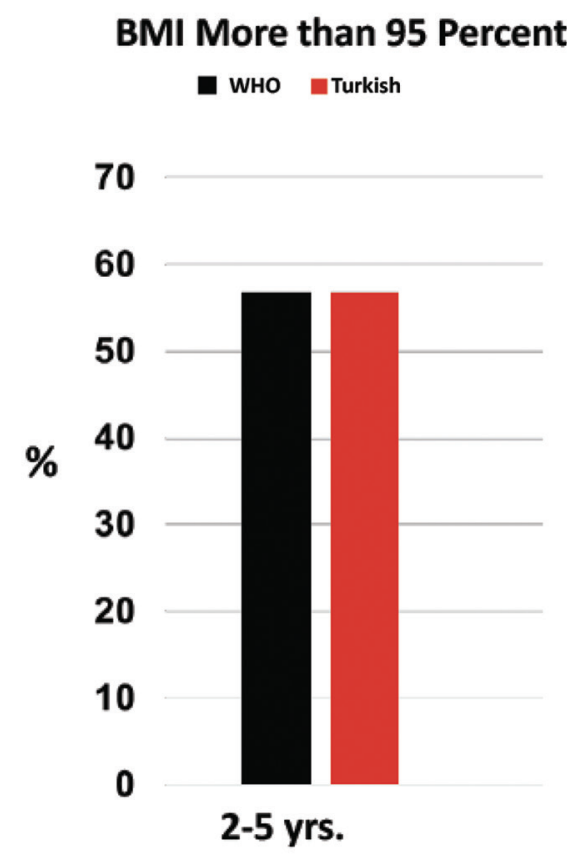

Figure 5. Prevalence estimates of obesity in the children's sample according to the Turkish and World Health Organization standards

BMI: body mass index

larger than $0.3 \mathrm{~cm}$ (height/length), $0.15 \mathrm{~kg}$ (weight), and 0.1 $\mathrm{kg} / \mathrm{m}^{2}$ (BMI) were significant at the 0.05 levels.

In the age groups from 3.5 to 18 years, absolute differences between Turkish children and WHO standards, which were larger than $1 \mathrm{~cm}$ (height), $1 \mathrm{~kg}$ (weight), and $0.5 \mathrm{~kg} / \mathrm{m}^{2}$ (BMI) were significant at the 0.05 levels.

\section{Discussion}

The implementation of incorporating WHO standards into pediatric practice has been the subject of debate in many countries, especially in those using national reference data for child growth evaluation. A number of studies have been published indicating that the new WHO Growth Standards do not fit with national references, including for Dutch, Belgian, Norwegian, Danish, and German populations $(3,6,21,22)$. Populations in these countries demonstrate tall stature and a large number of children have length/height above +2 SD according to the WHO 2006 Growth Standards. The study on the growth of Belgian and Norwegian children showed that the proportion of children below -2 SD of the WHO Growth Standards was lower and that above 2 SD of the WHO Growth Standards was higher in length/height, weight, BMI, and head circumferences (6). The applicability of the new WHO Child Growth Standards to the East Asian populations was studied by Hui et al (4) who found that Hong Kong Chinese children were generally shorter and fatter than the WHO standards. Due to higher birth weight in the UK90 reference compared to the WHO standards, growth curves for pre-term children and for the age 0-14 days were preserved, but for the other ages, the WHO standards are used $(23,24)$. Also, in the US, using the WHO standards was recommended by the $\mathrm{CDC}$ expert panel for children from birth to 24 months only (12). 
Except for the first 6 months and 3 to 6 years of age, BMI values were higher in Turkish children than WHO standards. After 3 months of age, the weight and length/ height values of the infants and children in our study were well above the WHO Growth Standards. Heights were essentially similar in the Turkish and WHO data at ages between 3 and 10 years but Turkish children were notably taller compared to the WHO curves after age 10 years. Although not well documented, population differences in growth become more striking in older children and during puberty. These differences are probably associated with earlier development of puberty in Turkish children $(25,26)$. To compare national and WHO growth references and explore their differences in assessing growth, a group of Turkish children between 0-5 years of age who attended outpatient clinic was measured. Differences between the two references in the evaluation of weight and height status in a group of Turkish children are highlighted in Figures 4 and 5. The highest prevalence of underweight and short stature was recorded using the WHO reference. With regards to obesity, estimations using the Turkish and WHO references were identical.

Hui et al (4) reported that Hong Kong Chinese toddlers at 3 years of age were, on average, shorter when compared with the WHO growth standards. The researchers speculated that this difference may be due to the result of epigenetic constraints on growth rather than failure to thrive or stunting due to less optimal living conditions. It is known that there are marked differences in final height among countries, even among those that are equally well off and also geographically close to one another $(27,28,29)$. Eveleth and Tanner, reviewing reports from different populations, stated that growth and body proportions are determined by the genetic constitution of the population. Comparing western European populations to those in the eastern part of the world, the authors stated that western populations are longer limbed and taller (30). Indeed, we also found in one of our studies that Turkish children have a higher sitting height/height ratio than Dutch children and lower than Chinese children, supporting the statement of the authors on the influence of genetic differences (31). Since the WHO study is a mixture of populations from different parts of the world with different backgrounds and different growth potential, the WHO study appears to have underestimated the genetic influence. Yet, it seems that genetic influence is very important. Most studies comparing the use of the WHO standards as countryspecific growth references suggest that the latter may describe the growth of children more faithfully than the WHO standards $(21,22)$.

\section{Study Limitations}

The limitation of our study is that data were analysed cross-sectionally. Because the majority of the children were followed for different periods of time, so longitudinal data covering ages 6 to 18 were not available for all children, although a relatively large sample size was attained for this national study. The other limitation of the study is the sample of the child population aged 0-5 years was based on a relatively well-off urban population.

\section{Conclusion}

In conclusion, as has been reported in many other countries, WHO growth standards do not precisely reflect the growth of Turkish children and may substantially alter the prevalence of short stature and underweight in Turkish children 0-5 years of age. We suggest that the WHO's growth standards can be used to compare the growth and development of children from different countries. However, when assessing the nutritional and growth status of children, national growth standards, where available, may be more appropriate.

\section{Ethics}

Ethics Committee Approval: The study was approved by the Institutional Ethical Review Board of İstanbul University, İstanbul Faculty of Medicine (protocol no: 1272, date: 26.06.2015).

Informed Consent: Written parental consent was obtained with the help of the school administration.

Peer-review: Externally peer-reviewed.

\section{Authorship Contributions}

Concept: Rüveyde Bundak, Olcay Neyzi, Gülbin Gökçay, Zehra Yavaș Abalı, Hülya Günöz, Feyza Darendeliler, Design: Rüveyde Bundak, Gülbin Gökçay, Hülya Günöz, Firdevs Baş, Data Collection or Processing: Rüveyde Bundak, Gülbin Gökçay, Firdevs Baş, Zehra Yavaş Abalı, Hülya Günöz, Feyza Darendeliler, Analysis or Interpretation: Andrzej Furman, Rüveyde Bundak, Zehra Yavaş Abalı, Literature Search: Rüveyde Bundak, Olcay Neyzi, Zehra Yavaş Abalı, Writing: Olcay Neyzi, Rüveyde Bundak, Zehra Yavaş Abalı.

Financial Disclosure: The authors declared that this study received no financial support.

\section{References}

1. WHO Multicentre Growth Reference Study Group. WHO Child Growth Standards based on length/height, weight, and age. Acta Paediatr Suppl 2006;450:76-85. 
2. de Onis M, Onyango AW, Borghi E, Siyam A, Nishida C, Siekmann J. Development of WHO growth reference for school-aged children and adolescents. Bull World Health Organ 2007;85:660-667.

3. van Buuren S, van Wouwe JP. WHO child growth standards in action. Arch Dis Child 2008;93:549-551

4. Hui LL, Schooling CM, Cowling BJ, Leung SSL, Lam TH, Leung GM. Are universal standards for optimal infant growth appropriate? Evidence from a Hong Kong Chinese birth cohort. Arch Dis Child 2008;93:561565. Epub 2007 Jun 7

5. Fenn B, Penny ME. Using the new World Health Organisation growth standards: differences from 3 countries. J Pediatr Gastroenterol Nutr 2008;46:316-321.

6. Júliusson PB, Roelants M, Hoppenbrouwers K, Hauspie R, Bjerknes R. Growth of Belgian and Norwegian children compared to the WHO growth standards: prevalence below -2 and above $+2 \mathrm{SD}$ and the effect of breastfeeding. Arch Dis Child 2011;96:916-921. Epub 2009 Nov 30

7. Ziegler EE, Nelson SE. The WHO growth standards: strengths and limitations. Curr Opin Clin Nutr Metab Care 2012;15:298-302.

8. Vignerová J, Paulová M, Shriver LH, Riedlová J, Schneidrová D, Kudlová E, Lhotská L. The prevalence of wasting in Czech infants: a comparison of the WHO child growth standards and the Czech growth references. Matern Child Nutr 2012;8:249-258. Epub 2010 Sep 29

9. Yang Z, Duan Y, Ma G, Yang X, Yin S. Comparison of the China growth charts with the WHO growth standards in assessing malnutrition of children. BMJ Open 2015;5:e006107.

10. Wright C, Lakshman R, Emmet P, Ong KK. Implications of adopting the WHO 2006 Child Growth Standard in the UK: two prospective growth studies. Arch Dis Child 2008;93;566-569. Epub 2007 Oct 1

11. Wright CM, Williams AF, Elliman D, Bedford H, Birks E, Butler G, Sachs M, Moy RJ, Cole TJ. Using the new UK-WHO growth charts. BMJ 2010;340:c1140

12. de Onis M, Garza C, Onyango AW, Borghi E. Comparison of the WHO child growth standards and CDC 2000 growth charts. J Nutr 2007;137:144-148.

13. Scherdel P, Botton J, Rolland-Cachera MF, Léger J, Pelé F, Ancel PY, Simon C, Castetbon K, Salanave B, Thibault H, Lioret S, Péneau S, Gusto G, Charles MA, Heude B. Should the WHO Growth Charts Be Used in France? PLoS One 2015;10:e0120806.

14. Gökçay G, Furman A, Neyzi O. Updated growth curves for Turkish children aged 15 days to 60 months. Child Care Dev 2008;34:454-463. Epub 2008 Apr 3

15. Neyzi O, Furman A, Bundak R, Günöz H, Darendeliler F, Baş F. Growth references for Turkish children aged 6 to 18 years. Acta Paediatr 2006; $95: 1635-1641$

16. Bundak R, Furman A, Günöz H, Darendeliler F, Baş F, Neyzi O. Body mass index references for Turkish children. Acta Paediatr 2006;95:194198.
17. Neyzi O, Bundak R, Gökçay G, Günöz H, Furman A, Darendeliler F, Baş F. Reference Values for Weight, Height, Head Circumference, and Body Mass Index in Turkish Children. J Clin Res Pediatr Endocrinol 2015;7:280-293.

18. Neyzi O, Alp H, Orhon A. Sexual maturation in Turkish girls. Ann Hum Biol 1975;2:49-59.

19. Cole TJ. Fitting smoothed centile curves to reference data. J R Statist Soc 1988;151:385-418.

20. Cole TJ. The LMS method for constructing normalized growth standards. Eur J Clin Nutr 1990;44:45-60.

21. Tinggaard J, Aksglaede L, Sørensen K, Mouritsen A, Wohlfahrt-Veje C, Hagen CP, Mieritz MG, Jørgensen N, Wolthers OD, Heuck C, Petersen JH, Main KM, Juul A. The 2014 Danish references from birth to 20 years for height, weight and body mass index. Acta Paediatr 2014;103:214224. Epub 2013 Dec 3

22. Rosario AS, Schienkiewitz A, Neuhauser H. German height references for children aged 0 to under 18 years compared to WHO and CDC growth charts. Ann Hum Biol 2011;38:121-130. Epub 2010 Oct 13

23. Cole TJ, Williams AF, Wright CM; RCPCH Growth Chart Expert Group. Revised birth centiles for weight, length and head circumference in the UK-WHO growth charts. Ann Hum Biol 2011;38:7-11.

24. Cole TJ, Wright CM, Williams AF; RCPCH Growth Chart Expert Group. Designing the new UK-WHO growth charts to enhance assessment of growth around birth. Arch Dis Child Fetal Neonatal Ed 2012;97:219222. Epub 2011 Mar 11

25. Bundak R, Darendeliler F, Günöz H, Baş F, Saka N, Neyzi O. Analysis of puberty and pubertal growth in healthy boys. Eur J Pediatr 2007;166:595-600. Epub 2006 Nov 11

26. Bundak R, Darendeliler F, Günöz H, Baş F, Saka N, Neyzi O. Puberty and Pubertal Growth in Healthy Turkish Girls: No evidence for secular trend. J Clin Res Ped Endocrinol 2008;1:8-14. Epub 2008 Aug 2

27. Roede MJ, Van Wieringen JC. Growth diagrams 1980: Netherlands third nationwide survey. Dutch. Tijdschr Soc Gezondheidsz 1985;63:1-34.

28. Cole TJ. The use and construction of anthropometric growth reference standards. Nutr Res Rev 1993;6:19-50.

29. Karlberg J, Cheung YB, Luo ZC. An update on the update of growth charts. Acta Paediatr 1999;88:797-802.

30. Eveleth PB, Tanner JM. Worldwide variation in human growth. In: Eveleth PB, Tanner JM (eds). Cambridge Studies in Biological \& Evolutionary Anthropology. Cambridge Univ Press, Cambridge, 1990.

31. Bundak R, Baş F, Furman A, Günöz H, Darendeliler F, Saka N, Poyrazoğlu $\mathrm{S}$, Neyzi O. Sitting height and sitting height/height ratio references for Turkish children. Eur J Pediatr 2014;173:861-869. Epub 2014 Jan 9 